\title{
A Socio-Ecological Approach to Mitigating Wildfire Vulnerability in the Wildland Urban Interface: A Case Study from the 2017 Thomas Fire
}

\author{
Crystal A. Kolden ${ }^{1, *(1)}$ and Carol Henson ${ }^{2}$ \\ 1 Department of Forest, Rangeland, and Fire Sciences, University of Idaho, 875 Perimeter Dr. MS 1133, \\ Moscow, ID 83844, USA \\ 2 Geo Elements, LLC, Leeds, UT 84746, USA; carol@geoelementsllc.com \\ * Correspondence: ckolden@uidaho.edu; Tel.: +1-208-885-6018
}

Received: 12 January 2019; Accepted: 8 February 2019; Published: 11 February 2019

\begin{abstract}
Wildfire disasters are one of the many consequences of increasing wildfire activities globally, and much effort has been made to identify strategies and actions for reducing human vulnerability to wildfire. While many individual homeowners and communities have enacted such strategies, the number subjected to a subsequent wildfire is considerably lower. Furthermore, there has been limited documentation on how mitigation strategies impact wildfire outcomes across the socio-ecological spectrum. Here we present a case report documenting wildfire vulnerability mitigation strategies undertaken by the community of Montecito, California, and how such strategies addressed exposure, sensitivity, and adaptive capacity. We utilize geospatial data, recorded interviews, and program documentation to synthesize how those strategies subsequently impacted the advance of the 2017 Thomas Fire on the community of Montecito under extreme fire danger conditions. Despite the extreme wind conditions and interviewee estimates of potentially hundreds of homes being consumed, only seven primary residences were destroyed by the Thomas Fire, and firefighters indicated that pre-fire mitigation activities played a clear, central role in the outcomes observed. This supports prior findings that community partnerships between agencies and citizens are critical for identifying and implementing place-based solutions to reducing wildfire vulnerability.
\end{abstract}

Keywords: hazard; California; vulnerability; fuel treatment; exposure; adaptive capacity; defensible space; wildland-urban interface; sensitivity

\section{Introduction}

The wildland-urban interface (WUI), the area where communities meet and intersperse with wildland vegetation, is the fastest growing type of land used in conterminous United States, having increased in area by one-third from 1990-2010 [1]. The WUI is increasingly at-risk of wildfire disasters, both from an increase in the number of wildfire ignitions and large fires due to humans [1-5], but also due to increased fire activity and large fires associated with anthropogenic climate change $[6,7]$. Recent years have seen a multitude of large wildfire disasters in the WUI that have set contemporary records for fire size, fatalities, and extreme fire behavior [8-12]. With housing units in the WUI projected to increase in the US [1], and anthropogenic climate change expected to further exacerbate extreme fire activity across many regions globally [13], it is well-recognized that there is a critical need to identify and enact mitigation solutions to reduce individual and community vulnerability to wildfires [14,15].

To reduce wildfire vulnerability, it is necessary to understand the contributing factors. Wildfire vulnerability is a product of three characteristics: (1) exposure to the hazard, (2) sensitivity of the 
population exposed (i.e., susceptibility to negative impacts), and (3) adaptive capacity (i.e., the ability to prepare for and/or recover from a wildfire based on available resources) [16-18]. The vast majority of efforts to reduce vulnerability to wildfire have been focused on reducing exposure to the hazard, as evidenced in a long history of firefighting and fire prevention [19]. Following the recognition that not only is $100 \%$ suppression impossible and many ecosystems are actually fire-dependent [20], exposure reduction efforts in the contemporary period have shifted toward reducing the negative impacts of fires. This is primarily accomplished through reducing fire intensity and heat generation by reducing the vegetative fuels available to burn, improving fire management effectiveness in critical locations through technological advances such as modeling fire behavior, and reducing the potential for homes and communities to be damaged by reducing flammability of the materials used in infrastructure and the built environment [14]. While biophysical studies have quantified how reducing wildfire exposure is theoretically accomplished through fuel manipulation, these primarily utilize empirical modeling of fire behavior to do so [21-24], with comparatively limited studies assessing the effectiveness of fuel reduction activities post-fire, and a primary emphasis on fire effects [25-27]. In addition, much of the scientific literature has focused on well-defined fuel treatment blocks and shaded fuel breaks [28,29], and is overwhelmingly focused on federal lands, where most of the fuel reduction work associated with the 2003 Healthy Forests Restoration Act occurs [25,30]. This stems both from a perception that most destructive wildfires ignite on federal lands and subsequently burn onto private lands [31,32], but also where federal agencies control management actions. There has been only limited assessment of small-scale fuel reduction as a means of reducing exposure on private or non-federal property, despite considerable theoretical emphasis on reducing fuel in the home ignition zone as part of a defensible space strategy [30,33,34].

By contrast, there is a robust but distinctly different literature addressing the other two elements of reducing wildfire vulnerability: the sensitivity and adaptive capacity of exposed populations. Several studies have highlighted the need for place-based vulnerability-reduction strategies to account for local variability in sensitivity and adaptive capacity [35-38]. This stems from the premise that a population with relatively greater sensitivity and reduced adaptive capacity will suffer more negative consequences from exposure as compared to a population with reduced sensitivity and greater adaptive capacity. In November 2018, this relationship was made clear during the so-called Camp Fire in northern California, USA, which consumed much of the town of Paradise (including over 13,000 structures), resulting in 86 fatalities-the highest number in the USA in a century [39]. A disproportionately high number of fatalities were older retired and disabled residents, reflecting the demographics of a low-income retirement town as compared to California overall. By contrast, the Woolsey Fire burned through the wealthy Malibu area of southern California simultaneous to the Camp Fire, and while the Woolsey Fire still consumed 1643 structures and produced three fatalities, these totals were a small fraction of the losses from the Camp Fire. While many factors contributed to these contrasting outcomes, they clearly demonstrate the need to address the sensitivity and adaptive capacity of a population when identifying vulnerability reduction solutions, and tailor prospective solutions to the demography of a given community [38].

The concept of developing community-specific, place-based strategies for reducing wildfire vulnerability is supported by the extensive fire social science literature, which addresses perceptions of wildfire and how perceptions translate to actions. Wildfire social science has been critical to informing development of vulnerability reduction strategies, particularly through understanding the relationship and feedbacks between the individual, the community, and the landscape in order to identify specific pathways towards actionable mitigation outcomes [38]. These pathways are based on general community archetypes that describe the sensitivity and adaptive capacity of a community and point to methods for inciting engagement and action that stem from individual perceptions, desires, and capacities $[38,40,41]$.

Implementation of risk-reduction pathways relies upon key social networks for information distribution, which is a critical feature of disrupting the so-called wildfire risk socio-ecological 
pathology [42-44]. It similarly relies upon local engagement and specific types of interactions between critical actors to develop implementable, realistic solutions [45]. Paveglio and colleagues [46] highlight the need for a "science of practice" surrounding the development of local wildfire mitigation pathways; they urge improved documentation of how adaptation was implemented and the outcomes as residents seek to "live with wildfire."

We suggest that a "science of practice" is not limited to the social aspect of wildfire adaptation and should be encouraged across the wildfire socio-ecological system. That is, scientists should seek to document and understand the confluence of social, ecological, and biophysical factors associated with implementing fire adaptation pathways, and the outcomes when a wildfire occurs. In a vulnerability framework, this means understanding how communities mitigate their vulnerability to wildfires by reducing their biophysical exposure, tailoring mitigation strategies to the sensitivities of the population, and capitalizing on strengths to improve adaptive capacity $[17,18]$. To do so successfully requires understanding both the social and ecological agents, however, case studies of specific fire events have generally focused on the social or the biophysical, and not both.

Here, we document both the social and the biophysical vulnerability reduction strategies taken by the community of Montecito, California in Santa Barbara County, USA, prior to the 2017 Thomas Fire, and how those strategies translated into outcomes. Montecito is one of the many communities in the United States that has been repeatedly exposed to wildfires over the last several decades [47], with multiple disastrous events (Figure 1). As such, the Montecito Fire Protection District (MFPD) embarked on an effort to reduce wildfire vulnerability in the community two decades ago. That effort was subsequently tested in the December 2017 Thomas Fire, which consumed over 1000 homes and became the largest wildfire in contemporary California history for several months until it was surpassed in 2018. Most of the homes were consumed at the outset of the Thomas Fire on days when strong downslope winds (i.e., Santa Ana and Sundowner winds) prevailed, and extreme fire behavior including long runs and long-range spotting, occurred, overwhelming fire suppression efforts. By contrast, Montecito experienced relatively little infrastructure damage from the Thomas Fire, despite similar conditions, including extreme fire behavior and the presence of Sundowner winds on the day the fire beset the community (16 December 2018).

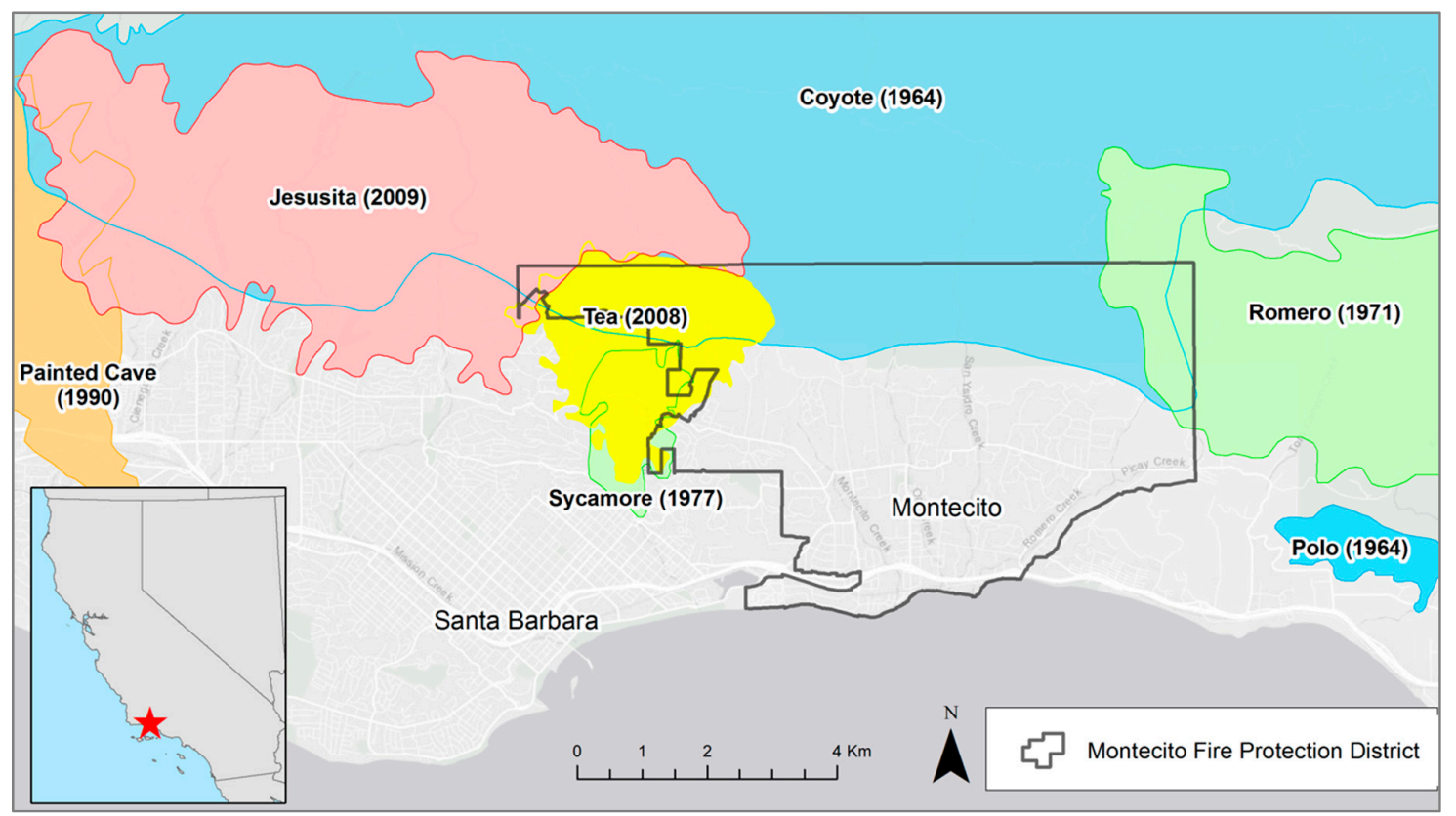

Figure 1. Study area and large fire history 1950-2017 (does not include the Thomas Fire).

Given the extreme conditions, in addition to the unrealized potential for considerable home and infrastructure loss, our objective was to document and synthesize the observed outcome associated 
with the Thomas Fire, namely the low negative consequences relative to the high potential. Specifically, we sought to (1) understand what social and biophysical vulnerability reduction strategies MFPD implemented over the last two decades, and (2) connect those strategies to the post-fire outcomes of the 2017 Thomas Fire by analyzing interview data collected by MFPD, ancillary records, and geospatial analysis.

\section{Materials and Methods}

\subsection{Study Area}

Montecito, California, is an unincorporated coastal community of just under 9000 people in southwestern Santa Barbara County, covering approximately 24 sq.km. Across the northern portion of the community, Montecito borders the Los Padres National Forest administrative boundary for approximately $10 \mathrm{~km}$, and the entire community is classified as a WUI Community-at-Risk due to the relatively low density of homes and high quantity of vegetative biomass across the community (Figure 1) [47]. The vegetation includes both the native chaparral shrub species and introduced landscaping vegetation, some of which has become invasive over decades. The most common types of landscaping vegetation that become fuel for wildfires include eucalyptus trees, cypress, juniper, and various grasses. Montecito is one of the most affluent communities in the state, with a median assessed home price of $\$ 4.4 \mathrm{~m}$ USD [48], however, like most communities there is high variability in income among residents, with a lower-income population present as well. Generally, residents have a higher level of education, are a greater proportion Caucasian, and have a higher median income than surrounding areas of southern California.

Like many coastal southern California communities, Montecito has experienced many wildfires over the last several decades, some of which resulted in fatalities, consumed homes, and had other negative impacts. These include the 1964 Coyote Fire (106 structures consumed), the 1971 Romero Fire (4 fatalities; 9 structures), the 1977 Sycamore Canyon Fire (195 structures), the 2008 Tea Fire (210 homes), and the 2009 Jesusita Fire (80 homes) (Figure 1). The entirety of Montecito is classified as a Very High Fire Hazard area by the California Department of Forestry and Fire Protection (CAL FIRE), stemming from both the high vegetative fuels component in the community and the fire environment. The most destructive and fatal wildfires in Santa Barbara County have all occurred during a katabatic wind event known locally as a Sundowner; this wind occurs throughout the year and is associated with amplification of downslope, offshore winds through alignment of upper level winds perpendicular to the east-west running Santa Ynez Mountains [49].

Wildfire was a relatively frequent occurrence prior to the modern period in the Santa Barbara region, with a large fire occurring every 20-30 years on average [50]. These fires were primarily ignited by the Chumash native people who inhabited the region at a relatively high density prior to being displaced or exterminated by European settlements; some fires also were ignited by summer lightning at high elevations that held over into autumn and grew into large fires with the onset of autumn wind events $[50,51]$. This pattern of ignitions has changed dramatically in the modern period, with a significant increase in human ignitions across the entire year extending the wildfire season, rather than being confined to a window from summer to autumn [2,52].

\subsection{Data Collected}

Two key data sources were utilized for this case report. First, the Montecito Community Wildfire Protection Plan (CWPP) was completed in early 2016 [48] and identified both wildfire hazard potential and damage potential. Following the 2017 Thomas Fire, Geo Elements, LLC, under contract with MFPD, conducted 14 interviews with individuals who were assigned to Montecito as fire suppression resources during the two days that the Thomas Fire directly impacted Montecito. These interviews were aggregated with geospatial and other ancillary data to develop a retrospective assessment and report [47] on the conditions under which the fire entered Montecito from the wildlands of the Los 
Padres National Forest, and how the pre-fire preparatory actions taken by MFPD ultimately impacted fire behavior and its effects in the community. Data from both the CWPP and the 2018 retrospective report (hereafter, the Retrospective report) were utilized for this case report with MFPD's permission. These data include interviews, fire history, program history and financial expenditures, infrastructure, predicted fire behavior outputs, defensibility, ember exposure, damage loss potential, fuel treatments, Thomas Fire progression reconstruction, video, and photos.

\section{Pre-Fire Vulnerability Reduction Strategies}

Based on the natural hazards vulnerability framework, we synthesized the pre-fire vulnerability reduction strategies and actions into reducing exposure to the hazard, addressing population sensitivity, and building adaptive capacity (Table 1). Following the Painted Cave Fire in neighboring Santa Barbara in 1990, MFPD identified areas of high fire hazard throughout the community and began a basic education program for residents of those areas. In 1994, MFPD created a new, temporary position-a Wildland Fire Specialist—specifically to facilitate programs that would reduce wildfire vulnerability, including hazardous fuel reduction, community engagement, code enforcement, and defensible space surveys. This individual became the chair of the newly-formed Santa Barbara Fire Safe Council in 1997 , an entity that was initially physically hosted by MFPD in an effort to increase communication and cooperation between the various fire management and response agencies in Santa Barbara County. In 1998, MFPD completed a Feasibility Assessment and Environmental Impact Report that identified fuel reduction priorities across the community, and in 1999 the Wildland Fire Specialist position was made permanent to support the implementation of this report. Another part-time Wildland Fire Specialist position was created to support the additional workload and by 2007, MFPD had 1.5 individuals whose primary objective was to reduce community vulnerability to wildfire (Figure 2).

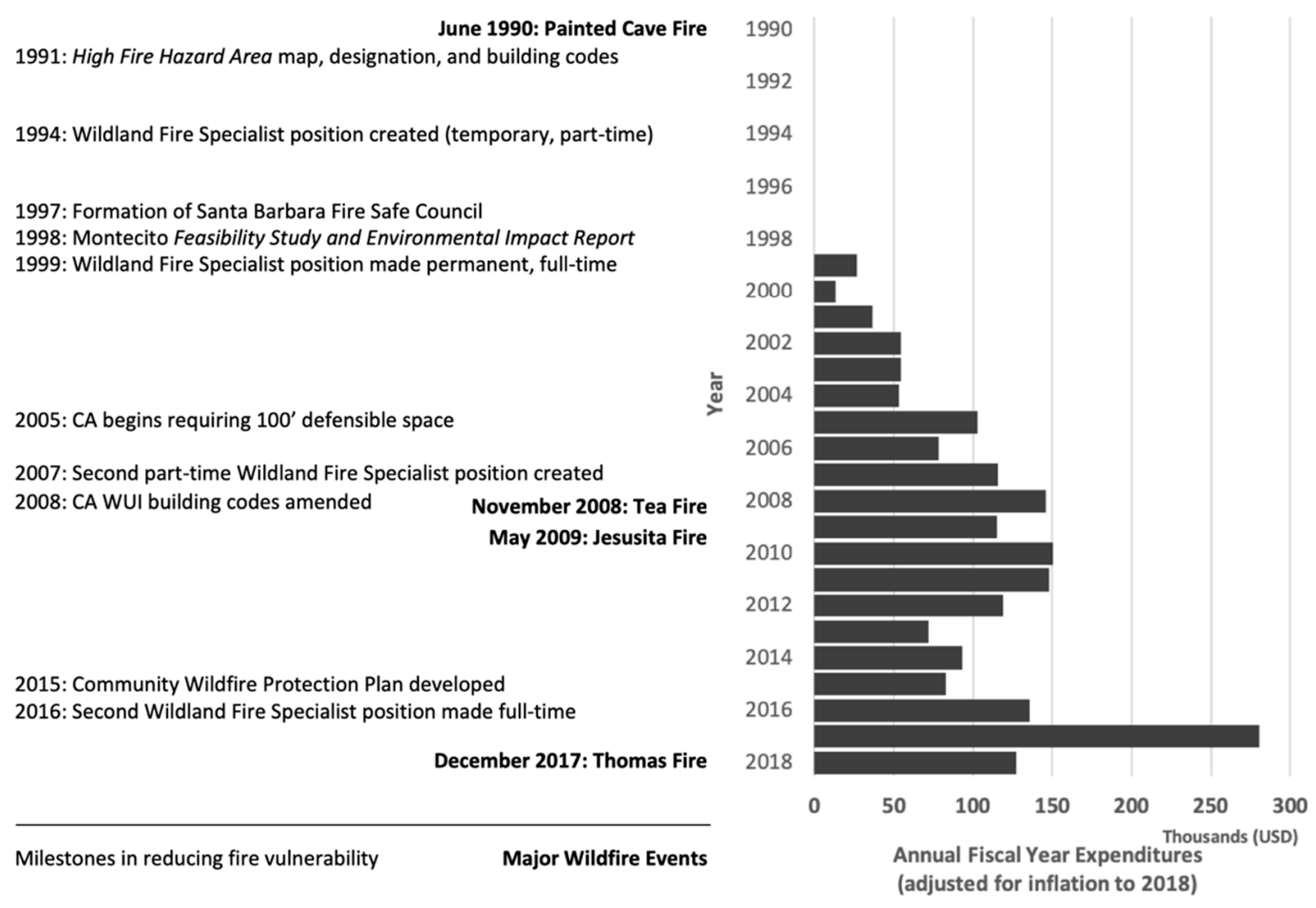

Figure 2. Timeline of Montecito Fire Protection District milestones, major fires, and annual budget (not including salary or benefits for Wildland Fire Specialists) dedicated to the Wildland Fire program. 
Table 1. Activities undertaken by Montecito Fire Protection District from 1998-2017 to reduce wildfire vulnerability.

\begin{tabular}{lll}
\hline \multicolumn{1}{c}{ Action } & Vulnerability Component(s) & Extent \\
\hline Create High Fire Hazard Area Map & Exposure, Adaptive Capacity & Community-wide \\
Hire Wildland Fire Specialist(s) & Exposure, Sensitivity, Adaptive Capacity & Community-wide \\
Form Santa Barbara Fire Safe Council & Exposure, Adaptive Capacity & County-wide \\
Feasibility Study and Environmental & Exposure, Adaptive Capacity & Community-wide \\
Impact Report & Exposure, Sensitivity, Adaptive Capacity & Community-wide \\
Community Wildfire Protection Plan & Exposure, Sensitivity & $\sim 200$ surveys/year \\
Defensible space surveys & Exposure, Sensitivity & Unknown \\
Defensible space improvements & Exposure, Sensitivity & $\sim 2000$ homeowners \\
Neighborhood Chipping Program & Exposure, Sensitivity, Adaptive capacity & 85 ha \\
Community fuel treatments & Exposure, Sensitivity & $\sim 21$ km of roads \\
Roadside fuel reduction & Exposure, Adaptive Capacity & Community-wide \\
Dead tree removal program & Exposure & Trailheads \\
Fire danger warning signs & Exposure, Adaptive Capacity & New permits/construction \\
Driveway widening & Exposure, Sensitivity & New permits/construction \\
New fire-resistant building codes & Exposure, Adaptive Capacity & Community-wide \\
Code enforcement & Sensitivity, Adaptive Capacity & Community-wide \\
Mailer education program & Exposure, Sensitivity, Adaptive Capacity & Community-wide \\
Evacuation pre-attack zone planning & & \\
\hline
\end{tabular}

Over the 20-year period between 1999 and 2018, the MFPD expended approximately \$1.76 million (mill) USD (\$2 mill USD adjusted for inflation to 2018) on wildfire vulnerability reduction activities (Figure 2). We include 2018 here as these are fiscal year totals, where the fiscal year ends June 30 of the year listed, so the Fiscal Year 2018 (FY2018) expenditures were primarily expended in autumn 2017, prior to the December ignition of the Thomas Fire (this also contributes to reduced FY2018 expenditures relative to prior years). When adjusted for inflation, it is clear that funding was inter-annually variable, but generally increasing over time (Figure 2).

Most of the activities undertaken by MFPD addressed more than one component of the vulnerability triangle (i.e., exposure, sensitivity, and adaptive capacity). Any action that specifically identified geospatial patterns of exposure to wildfire (e.g., defensible space surveys), or was designed to reduce direct exposure to wildfire (e.g., defensible space improvements, roadside fuel reduction) addressed exposure vulnerability. Any action that specifically identified populations in the community that are more sensitive to the negative ramifications of wildfire and determined population-specific actions designed to mitigate those ramifications addressed sensitivity vulnerability. Any action that increased the ability of the community to respond to wildfire and reduce the negative ramifications developed adaptive capacity. An action such as hiring a Wildland Fire Specialist, whose primary position is to build relationships with community members and facilitate programs to reduce vulnerability, addressed all three components of vulnerability.

First, the Wildland Fire Specialist reduced vulnerability by enacting other activities that directly reduce exposure, including fuel reduction projects that reduce fire behavior immediately adjacent to homes and roads, or activities that decrease the flammability of homes and infrastructure directly (reducing the chances that the humans occupying those structures will be exposed to flames or lose the structures, and suffer economic or personal losses). Second, the Wildland Fire Specialist addressed population sensitivity by engaging residents individually to develop a relationship and build trust. Such relationships are critical to overcoming the barriers which inhibit certain demographics from reducing vulnerability, including language barriers (e.g., engaging in Spanish with the Hispanic population), cultural barriers (e.g., reducing distrust of government entities and willingness to follow evacuation recommendations), disability barriers (e.g., developing evacuation plans for those unable to drive themselves and dependent upon others for transport), and economic barriers (e.g., finding solutions that are inexpensive/free or finding grant money to support individual properties or subdivisions). Third, the Wildland Fire Specialist increased adaptive capacity by improving planning and facilitating the types of activities that help communities recover more successfully and quickly 
during and following wildfires, such as helping residents evacuate more effectively (e.g., in a timely manner, with somewhere to go pre-identified, and with a "go-bag" or checklist of critical medicines or valuables that the resident needed), reducing structure loss, and reducing critical municipal infrastructure damage and loss (e.g., roads, municipal water supply, and schools).

Conducting community-wide assessments such as the High Fire Hazard map creation and the feasibility study addressed exposure by identifying where the greatest potential was for exposure to wildfire, and addressed adaptive capacity by subsequently using that information to educate the community. The CWPP that the MFPD completed in 2016 [48], further addressed both exposure and adaptive capacity by highlighting what areas of the community would be most exposed to ember cast and least defensible by firefighters, and identified vegetation management units where new fuel reduction projects could have the greatest effectiveness in facilitating fire suppression activities safely (both reducing exposure and increasing adaptive capacity; Figure 3). Furthermore, the CWPP also addressed sensitivity by specifically defining sensitive populations, identifying the proportion of Montecito residents belonging to some of these populations (e.g., age groups identified in the US Census), and noting the need for evacuation plans tailored to sensitive populations, including pets.

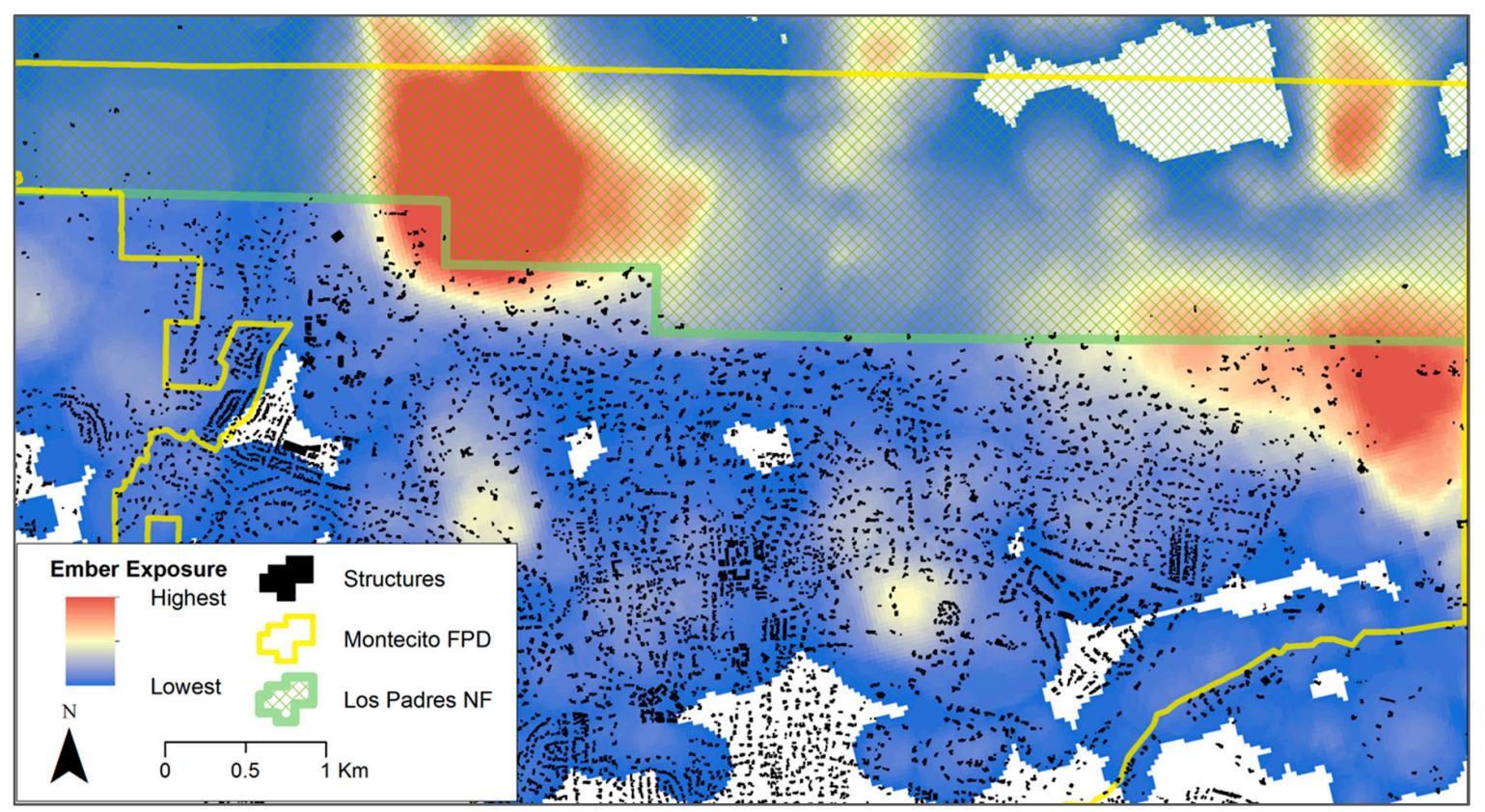

Figure 3. The Montecito Community Wildfire Protection Plan used fire modeling to geospatially characterize ember exposure and defensibility across the community with respect to structures, in order to prioritize key areas for future vulnerability reduction activities. (Adapted from [51]).

Fuel reduction activities in Montecito took many forms (Figure 4). On individual properties, the Fire Marshall and the Wildland Fire Specialist worked with property owners to reduce home ignition potential (i.e., ensuring the home did not serve as fuel for a fire). This was conducted using specific fire-resistant materials and structural modifications, and by increasing defensible space between the structure and the nearest flammable vegetation through removal of both live and dead trees, limbing up of trees, and replacement with less flammable landscaping (e.g., replacing native shrubs with succulents or herbaceous flora). Across the community, MFPD incentivized property owners to reduce woody materials on private property by implementing a neighborhood chipping program, wherein residents would relocate woody material to the end of their driveway on specified days, and MFPD contractors chipped and removed the materials. Similarly, MFPD implemented community fuel treatments on private property in strategic locations, using contract fuel removal crews. These treatments primarily occurred either along key road systems on the north side of the community to facilitate ingress, egress, and widen potential future fire lines; and behind private 
property to connect the road system network at critical points (Figures 4 and 5). Finally, MFPD initiated a partnership with the public utility, Southern California Edison, to remove the many dead and dying trees near power infrastructure, during the multi-year California drought that began in 2011. All of these activities reduce exposure and increase adaptive capacity (by reducing negative post-fire effects). It is also worth noting that the community-wide activities support sensitive populations by (1) recognizing that sensitive populations may require more time to evacuate, and improving ingress/egress through roadside fuel reductions that facilitate this, and (2) recognizing that not all residents are able to conduct exposure-reduction activities on their individual properties due to the conditions that make them sensitive populations in the first place (e.g., physical disability).

Evacuation and ingress/egress issues were key elements of two other activities undertaken by MFPD prior to 2017. First, MFPD improved ingress/egress and evacuation and fire suppression effectiveness by delineating pre-attack zones across the community in their wildland fire initial attack plan (Figure 5). MFPD utilized these pre-attack zones (which are essentially sub-units of the community that were delineated prior to firefighters attacking a future, hypothetical wildfire) in their community education efforts, planning process, and printed high-resolution paper maps of each zone that were pre-packed in a portable file box for distribution to non-MFPD fire suppression resources in the event of a wildfire. Nine of the interviewees noted the utility of these maps in facilitating greater life safety for firefighters and increased suppression effectiveness, because the maps were able to help resources not familiar with the area to navigate the community safely and quickly and find the pre-designated water sources and equipment staging areas in Montecito, which were also marked on the map.

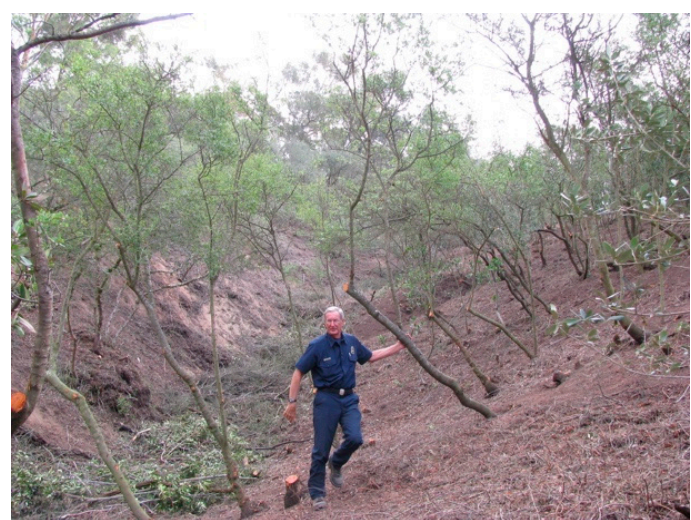

(a)

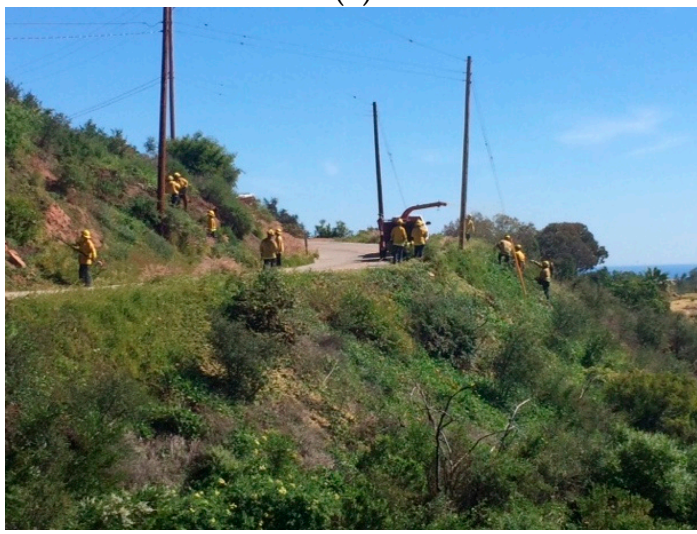

(c)

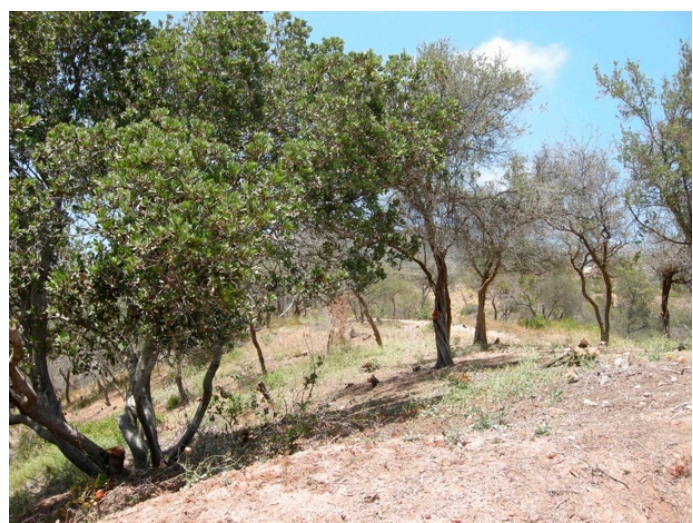

(b)

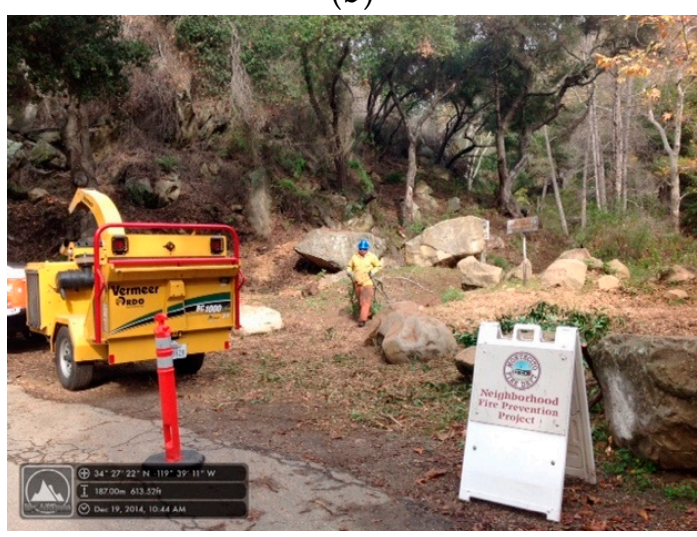

(d)

Figure 4. Examples of fuel reduction activities undertaken in Montecito: (a) a shaded fuel break on private property with Wildland Fire Specialist, (b) understory clearing and thinning on private property, (c) roadside fuel reduction, and (d) chipping equipment in use as part of the Neighborhood Chipping Program. Photos courtesy of Montecito Fire Protection District. 


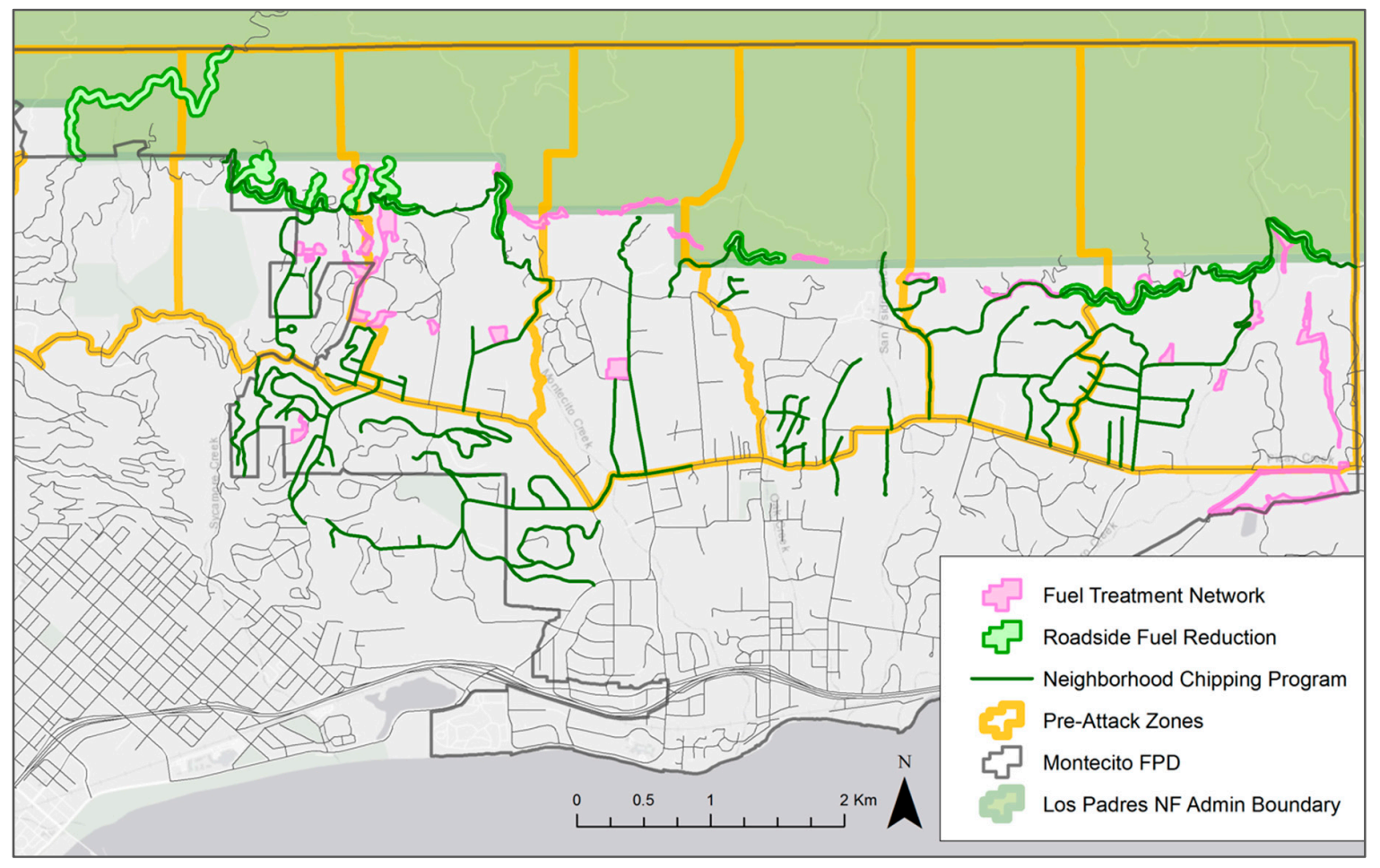

Figure 5. Location of different types of vulnerability reduction activities across the community of Montecito, including delineation of pre-attack zones used for evacuation planning, and fuel reduction treatments including Roadside fuel reduction efforts, the Neighborhood Chipping program, and the Fuel Treatment Network. (Adapted from [47]).

Second, while MFPD implemented several new fire codes focused specifically on structures (e.g., banning cedar shakes for roofing and siding, requiring boxed eaves), a new requirement for wider driveways focused on reducing exposure through improved evacuation, and increasing adaptive capacity by facilitating firefighter safety during fire suppression activities and post-fire clean up. In Montecito, as in many WUI communities, many of the homes are located at the end of long (>100 m), narrow, winding driveways that terminate at garages. Increasing driveway width and turnaround space supports larger fire apparatus and other large equipment allowed firefighters access these areas, and safely use a tactic referred to as "fire following." Fire following is frequently used during extreme conditions, wherein firefighters (1) prepare homes to resist an oncoming wildfire, (2) retreat from the home or neighborhood when extreme fire behavior and direct flames from the fire front threaten their life safety, and then (3) "follow" behind the flaming front and re-engage with the home or in the neighborhood. During this re-engagement, they focus on extinguishing portions of the structure that are on fire, extinguishing spot fires on the property, remove flaming debris from structures (e.g., flaming palm fronds on the roof or deck), and wetting down vegetation if there are additional threats for re-ignition (e.g., additional spot fires). Fire following depends on firefighters being able to safely navigate to a home and turn around so that they can evacuate rapidly if needed; driveway design is paramount to this dependency.

\section{Reconstructing the Thomas Fire in Montecito}

The Thomas Fire ignited on 4 December 2017 near Santa Paula, California, approximately $60 \mathrm{~km}$ east of Montecito. The fire began under a record-length Santa Ana katabatic wind event that facilitated large fire growth and consumed hundreds of structures during the first several days of the event [47]. The winds pushed growth primarily to the west (Figure 6), and by 15 December, the fire had reached the eastern edge of Montecito and was burning on the slopes uphill and to the north of the community (Figure 7). Sundowner katabatic winds were forecast to develop the morning of 16 December. 


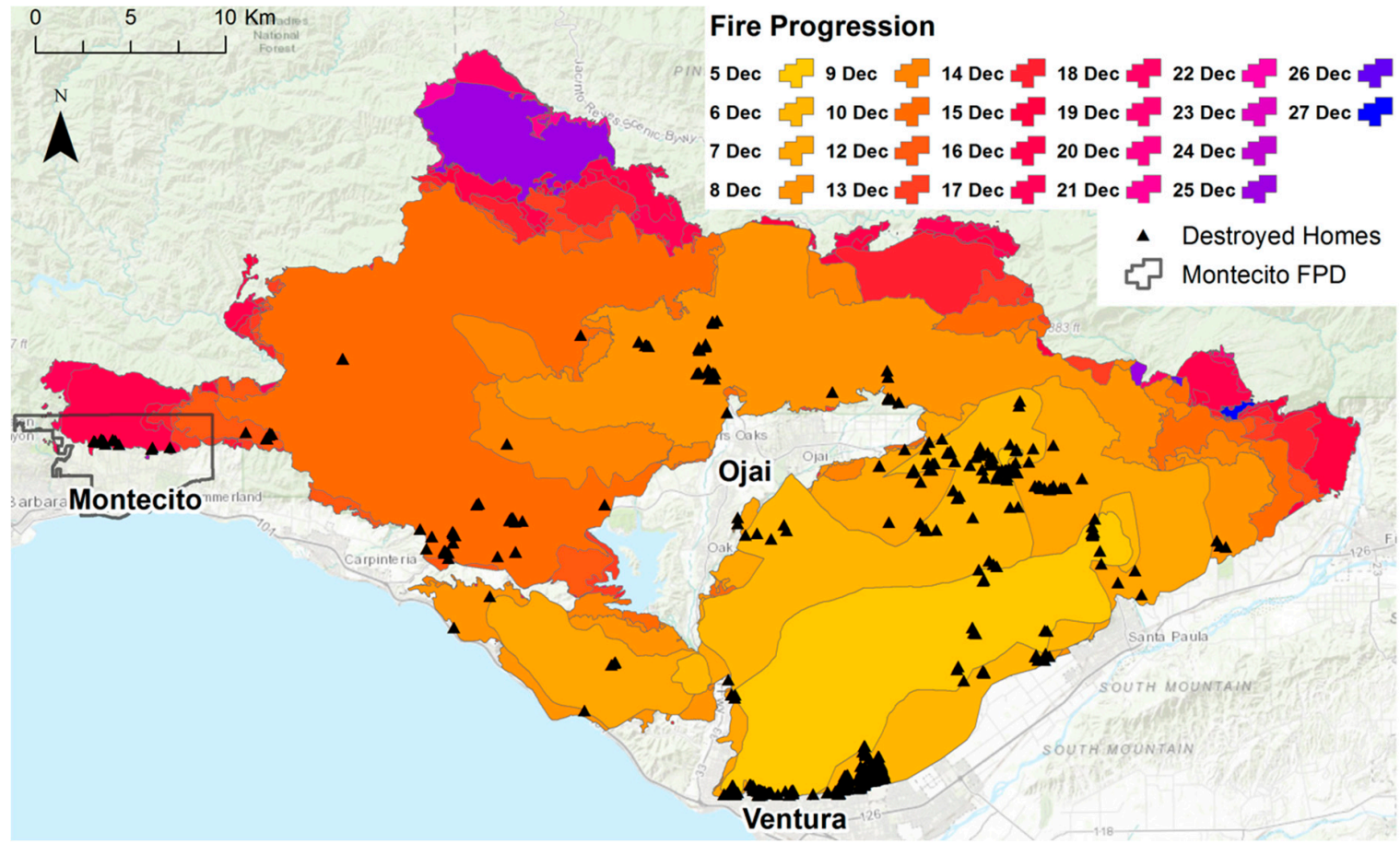

Figure 6. Thomas Fire progression for the entire fire from 4 to 27 December, the date the final perimeter was reached. The fire primarily impacted Montecito on 16 December 2017. (Adapted from [47]).

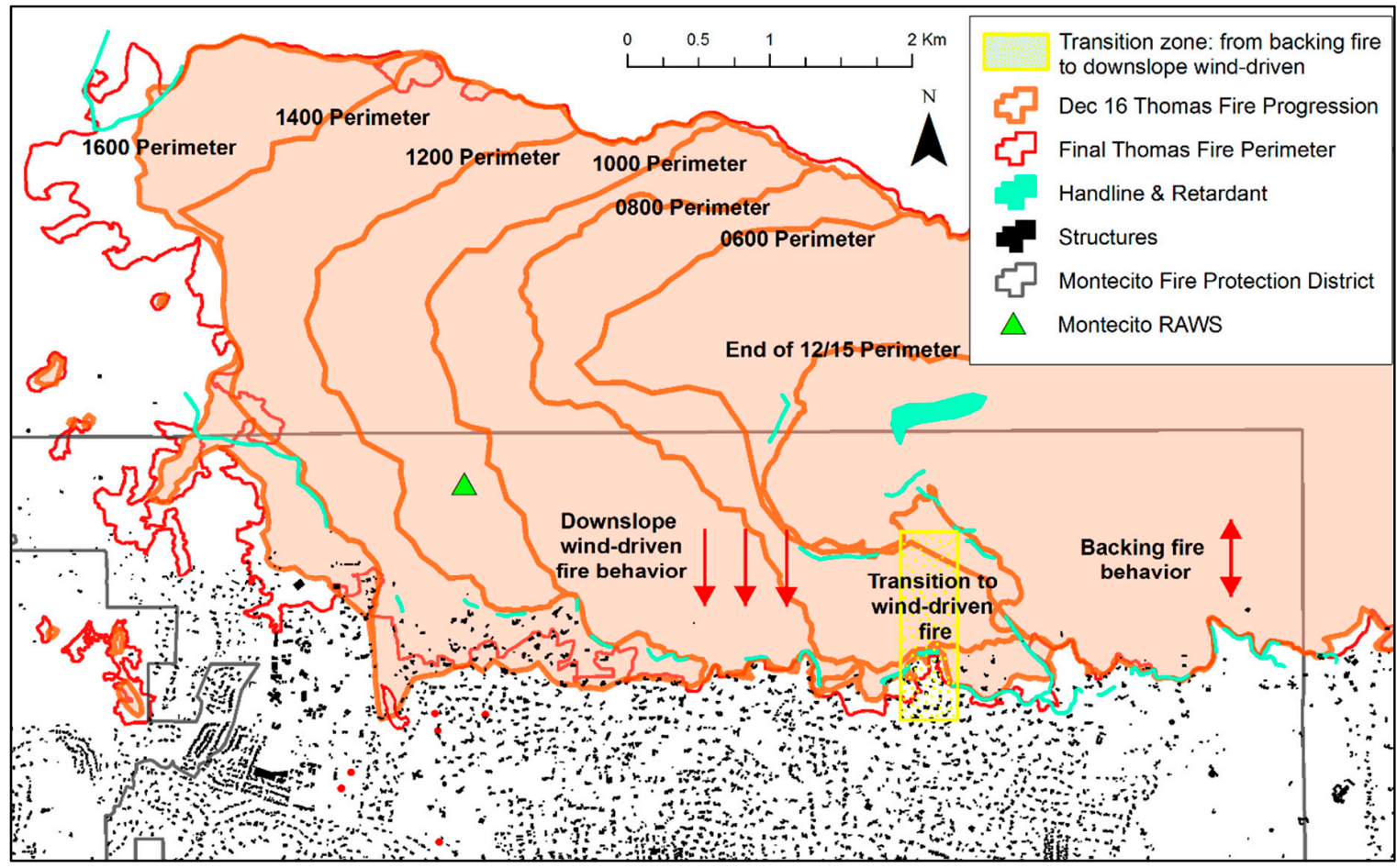

Figure 7. Thomas Fire progression on 16 December 2017, in the vicinity of Montecito, where the fire primarily moved westward, and was pushed downhill by Sundowner winds. (Adapted from [47]).

Interviews, damage records, satellite observations, and reconstruction of the fire progress for 16 December indicate that fire behavior that day was extreme, but that many of the pre-fire activities undertaken by MFPD had a direct outcome for fire impacts to the community. As forecasted, Sundowner winds developed around 06:00 hours local time, with sustained winds exceeding $13 \mathrm{~m} / \mathrm{s}$, 
and gusts exceeding $30 \mathrm{~m} / \mathrm{s}$ by 08:00 hours, when the Montecito Remote Automated Weather Station (RAWS) that was stationed at $450 \mathrm{~m}$ elevation above the community was consumed by the fire. Prior to the winds developing, interviewees indicated that they had primarily observed backing fire behavior, wherein the fire was able to advance downhill based on a continuous fuel bed without gaps, but with relatively reduced flame lengths and a slow rate of spread. However, once the Sundowners became established, fire behavior became wind-driven, with ember cast producing spotting in excess of $400 \mathrm{~m}$ ahead of the main fire front.

\section{Vulnerability Reduction Outcomes}

The Retrospective report [47] identified key areas where pre-fire mitigation activities supported fire suppression and reduced loss of both life and property, and also where homes were consumed and whether there had been any pre-fire mitigation. Based on the location of the final fire perimeter mapped by MFPD and Santa Barbara County personnel (Figure 7), there were 100 primary residences within the final fire perimeter, and 467 residences within $400 \mathrm{~m}$ (average fire spotting distance) of the final fire perimeter. Of these, seven primary residences were destroyed (i.e., primary dwelling unit, in contrast to a guest house or secondary dwelling unit), producing a 93\% protection rate within the perimeter. An additional 30 residences in the area received minor damage, leaving 430 residences in the core fire impact area (i.e., within the $400 \mathrm{~m}$ spotting distance of the perimeter) undamaged by the fire. We describe these outcomes here in the context of the three components of vulnerability.

\section{Exposure}

Fire suppression and effective evacuation were key components of reduced exposure to fire for Montecito. As the Thomas fire progressed from Ventura County into Santa Barbara County, evacuation was initiated 10 December, and nearly all of the residents in the evacuation area heeded the warning. Per interviewees, those residents that remained communicated closely with MFPD Wildland Fire Specialists and most evacuated on 16 December as the fire advanced towards their properties, but before their evacuation might hinder fire suppression activities. This advance evacuation allowed fire suppression resources to prepare properties and move freely on the low-visibility roads without the hazard of civilian vehicles. Many properties abutting the edge of the wildlands (i.e., the Los Padres National Forest administrative boundary) had small containment lines (i.e., "scratch lines"), fire retardant lines (both aerially and manually applied on the ground), or a plumbed hose lay (dry fire hoses ready to be attached to a fire engine or water tanker) along their edges that had been installed by firefighters in the days prior to 16 December.

The fire suppression resources themselves were another exposure reduction factor. Over 1100 fire personnel were assigned to the Montecito divisions of the Thomas Fire on 16 December; these being a mix of hand crews (e.g., elite firefighters known as hotshots), fire engine strike teams, bulldozers, water tenders, and individual resources. The fire crews were working in 24-hour shifts, with most individual crews working every other 24-hour shift, and an exchange occurring at 07:00 each morning. As the Sundowner winds developed at 06:00 and fire behavior became explosive shortly thereafter, many of the resources, which had been intended to leave the fire line at 07:00 remained engaged in the fire fight in Montecito throughout the morning. Thus, the timing of the increased winds and fire "blow up" produced a scenario where several hundred more fire suppression resources were engaged in the firefight than would have been earlier or later in the day; there were potentially between 1200 and 2000 individuals engaged. These resources made use of water and physical labor to reduce structure exposure to flames. Interviewees described this engagement as using both direct engagement, such as spraying water on decks and vegetation abutting homes, and fire following tactics, such as pulling flaming debris off roof and deck areas after the main front had passed. It is notable, however, that aerial firefighting resources such as helicopters and retardant tankers were not used in Montecito on 16 December, as strong winds grounded aircrafts. This is critical to note as it has been argued that aircraft are vital to suppression efforts, despite the high expense of aerial fire suppression [53]. 
The effectiveness of fire suppression efforts was directly supported by the pre-fire vulnerability reduction efforts undertaken by MFPD. Interviewees noted that they were able to use fire following tactics because homes were fire-resistant, giving firefighters time to engage and remove flammable debris before a structure became fully involved with fire. Firefighters also described being able to engage because most homes had sufficient defensible space to make it safe for them to do so, without fear of entrapment. This was of particular concern due to entrapment of firefighters that occurred on the nearby Jesusita Fire in 2009, which was associated with lack of defensible space and evacuation routes [54].

Interviewees also noted that suppression effectiveness was amplified by the reduction of roadside fuels, which allowed them to conduct backfiring operations along some parts of the road system and hold the fire along other segments. Interviewees described the difference between other portions of the Thomas Fire in Santa Barbara County, where heavy roadside vegetation created a "tunnel effect" that inhibited large fire apparatus passage (leading to over a dozen homes destroyed in one nearby canyon), and Montecito, where roadside clearance eliminated vegetation tunnels and facilitated two large city fire apparatus being able to pass each other on narrow roads. Videos taken by some interviewees further demonstrated how such clearance improved firefighter safety given the low visibility created by heavy smoke. Several firefighter fatalities in the US have been attributed to exiting the roadway due to lack of visibility in smoky conditions [55].

Both defensible space and roadside fuel treatments were supplemented by the community fuel treatments implemented by MFPD, which served to "link" together with the fuel reductions undertaken by residents and along roadways (Figure 8). All but one interviewee described this network of fuels reduction as being vital to effective suppression efforts and structure protection, specifically because it allowed firefighters to engage the fire safely. Of the seven primary residences destroyed in Montecito, two were located below a 'gap' in the fuel treatment network, and the loss of the remaining dwellings was primarily attributed to the presence of fuels immediately adjacent to the structure, and inaccessibility for firefighters to support the fire following tactic. These losses were attributed to fire exposure that was not mitigated.

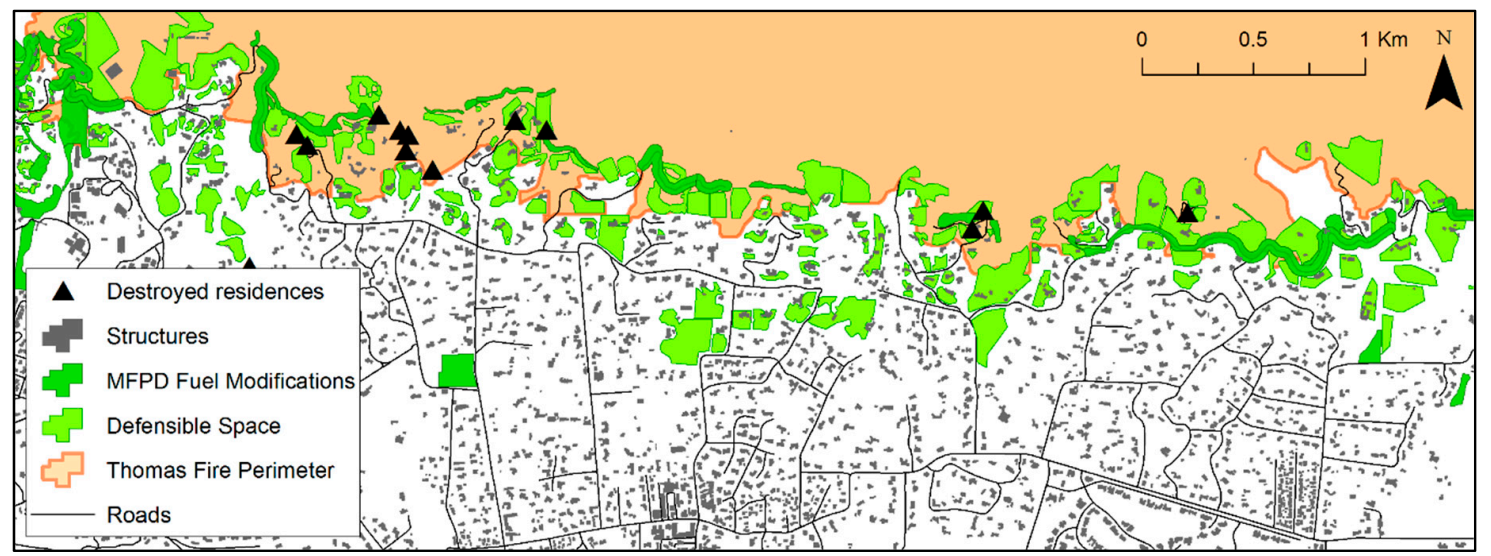

Figure 8. Montecito Fire Protection District fuel treatment network, homeowner defensible space, and locations of residences (both primary homes and guest houses) destroyed by the Thomas Fire in Montecito. (Adapted from [47]).

Finally, the planning efforts undertaken by MFPD to complete the 1998 Feasibility Report, the 2016 CWPP, and the pre-attack zone mapping all contributed to reduced exposure through increased understanding of where the potential problem areas were in the community, and how a cohesive strategy could be implemented to address wildfire vulnerability. These documents outlined the range of concerns, used models, and best practices to identify mitigation strategies. Several interviewees 
noted that the pre-attack planning maps were particularly useful in improving suppression safety and effectiveness as non-local resources navigated the community.

To be clear, much of the exposure reduction success can be attributed to the amount of time firefighters had to prepare for the arrival of the Thomas Fire to Montecito, including several days to evacuate residents so that the focus could be on fire suppression on 16 December. Without this preparation time, it is probable that more homes would have been consumed in Montecito, similar to the 210 homes consumed during the first few hours of the 2008 Tea Fire (where firefighters were almost entirely focused on evacuation). However, as the Retrospective report notes, the 2009 Jesusita Fire saw home losses, and a firefighter 'burnover' event supporting the conclusion that pre-fire exposure-reduction efforts in Montecito mitigated the potential for a repeat of this outcome, and amplified the effectiveness and safety of firefighter suppression activities. Such mitigation activities also support exposure reduction by giving residents more time to evacuate safely, and mere minutes can be the difference between life and death in an emergency evacuation.

\section{Sensitivity}

MFPD addressed sensitivity to wildfire in several key ways. They developed a community wildfire protection plan that directly addressed the diversity of the community and the additional challenges faced by some residents, both to prepare for wildfire and to evacuate. The Wildland Fire Specialist directly engaged with many of the vulnerable older residents, developing relationships, acquiring grant funds to support fuel reduction activities, and facilitating fuel reduction through contract crews that conducted the work on private property. At least one resident made it clear that this relationship was vital, both knowing when to evacuate and to her home surviving, as her home was within the wildfire perimeter but was undamaged in part due to considerable defensible space carved out by contract crews facilitated by MFPD. The type of outreach and public education conducted by MFPD further supports sensitive populations both by finding solutions specific to meet their needs and by ensuring that fire personnel know where individuals live who may require extra support during evacuation. Often first responders have no idea which residents may require extra time or assistance to evacuate, and such personal relationships can reduce associated negative outcomes. This is particularly important in light of several recent California wildfires where civilian fatalities were primarily older individuals and children, and media reports indicated that often the individuals killed did not have transportation to evacuate. These include the 2015 Valley Fire [56], the 2017 Tubbs Fire [57], and the 2018 Carr Fire [58], in addition to the 2018 Camp Fire as described in the Introduction.

It is also evident that the community fuel network supported sensitive communities by protecting the entire community, regardless of language, income level, physical ability, age, or education level. There is considerable discussion in the media as to whether home protection and life safety are primarily the responsibility of individuals who choose to live in the WUI and other high fire hazard areas. Such discussion fails to acknowledge sensitive populations, many of whom have limited ability to address wildfire risk where they live due to financial situation, language barriers, educational limitations, or family obligations. Santa Barbara County, for example, has one of the highest median home prices in the US, and many of the service industry and construction workers are immigrants or minimally educated individuals who work multiple jobs, have families to support, and rent (not own) their homes, making them less likely to be able to undertake expensive and time-consuming upgrades to homes and properties that they do not have legal ownership to alter. These individuals are protected by the efforts of their neighbors. An evaluation of fuel reduction across Montecito from high-resolution, multi-temporal satellite data revealed that when all fuel reduction, shrubland type conversion, defensible space landscaping, and fire roadside clearing work was mapped across the community within $400 \mathrm{~m}$ of the Thomas Fire perimeter, there was a nearly unbroken line from east to west of reduced fuel, and space for firefighters to conduct suppression operations (Figure 8); such efforts stemmed from the work of the MFPD and some citizens, but effectively reduced vulnerability to wildfire for all Montecito citizens. 


\section{Adaptive Capacity}

If adaptive capacity for wildfire is the ability to recover post-fire, then the first tenet of recovery is to reduce negative impacts as much as possible. As such, much of the pre-fire exposure reduction completed by MFPD was effective in boosting adaptive capacity, as most residents were able to return to their homes and resume normal routines within only a few days of the fire. Evacuation orders were lifted on 21st of December, and the initial lasting negative impact of the fire was on the Montecito municipal water supply, which was temporarily interrupted, and a boil-water order issued. It must be acknowledged that many Montecito residents have a relatively high adaptive capacity based on income levels, a diverse economic base, and high education levels providing individual flexibility in times of emergency. However, the considerable preparation for a wildfire event facilitated minimal negative impacts and allowed most residents to be temporarily inconvenienced rather than devastated by the wildfire itself.

This contrast between devastation and inconvenience was tragically illustrated in the early morning hours of 10 January 2018, when heavy rain on the recently burned hill-slopes above Montecito produced catastrophic debris flows of mud and rock, that resulted in 23 fatalities and over 500 homes destroyed or damaged in the community. The debris flow destroyed bridges and left mud over a meter deep on a major highway, interrupting the county transportation network and negatively impacting community services for months after the event. The debris flow illustrated the need for adaptive capacity to wildfire across the entire landscape; while Montecito negated the worst fire intensity and impacts, the Los Padres National Forest shrublands (where the debris flows originated) did not have sufficient ecological adaptive capacity, and the hill-slopes were consumed at such high intensity by the Thomas Fire that near complete consumption of organic material occurred. This was evident in the months following the fire, according to the Retrospective report, as there was minimal observed chaparral regeneration in the burned area above Montecito, despite chaparral species being adapted for rapid post-fire regeneration [59].

The debris flow event also revealed in one of the areas of adaptive capacity that Montecito did not adequately address: the potential for evacuation fatigue among residents and the impact of this fatigue on subsequent evacuation orders. Many Montecito residents were evacuated for up to two weeks or greater during the Thomas Fire. When the debris flow event was forecast (with a great deal of uncertainty due to the relative limitations of forecasting such events) and voluntary evacuation suggested, interviewees indicated that many residents did not evacuate, which proved fatal. As 15 of the 23 fatalities were elderly adults, children, and immigrants who did not natively speak English, this points to a need for improved sensitivity assessments and adaptation strategies.

\section{The Community Partnership}

In evaluating how MFPD approached reducing wildfire vulnerability across Montecito, it is clear that a community partnership at multiple spatial scales was critical for mitigating disaster, specifically loss of life and infrastructure, during the Thomas Fire. This community partnership took three forms (agency-agency, agency-resident, and resident-resident) and illustrates the range of individual and collective actions that facilitated the fire outcomes in Montecito during the Thomas Fire.

The agency-agency partnership is evident in how MFPD relates to, and interacts with, other fire management agencies across Santa Barbara County. Several of the non-MFPD interviewees noted their frequent interactions with MFPD, either on the Santa Barbara Fire Safe Council, or at training days held in cooperation around the county, or during wildfire events. One interviewee described a specific disaster response training event hosted only a few months prior to the Thomas Fire by MFPD, which allowed participants to see what types of fuel reduction were done around Montecito, a considerable asset when the Thomas Fire occurred. As breakdowns in interagency communication and cooperation have been frequently noted as a contributing factor to fire fatality events [60], establishing and maintaining agency-agency partnerships is a critical facet of reducing wildfire vulnerability. 
The agency-resident partnership is evident in the primary mission of the Wildland Fire Specialists employed by MFPD: to develop relationships and communicate with residents on issues relating to wildfire. The Wildland Fire Specialists are readily available to residents, and by their own accounting, spend most of their time visiting resident properties and directly engaging with residents to develop relationships. They help residents identify individual solutions for their properties and facilitate labor and additional support when needed. This removes much of the burden from residents and is consistent with the trust in government that Paveglio et al. [38] describe in their delineation of the four wildfire archetype communities. Montecito is not well-defined by a single community archetype; rather, it a mix of the 'Formal Suburban WUI' and 'High Amenity-High Resource' communities described by Paveglio et al. [38]. Montecito residents value their access to recreation, and the "natural" character of their community, and MFPD vulnerability reduction efforts must conform to these values. This is evident in the agency-resident partnership, where residents have allowed MFPD to install and maintain the fuel treatment network on their private property, but those treatments must conform to the natural look (e.g., thinning rather than complete removal of shrubs) and are excluded from the riparian zones where many of the popular hiking trails are.

Finally, the resident-resident partnership is more subtle, but became evident in the mapping of defensible space and fuel reduction around individual homes within $400 \mathrm{~m}$ of the fire line (Figure 8). While MFPD conducts defensible space surveys, these surveys are voluntary, and the interviewees indicated that there has been limited enforcement of the California defensible space requirements. While many of the residents developed defensible space in partnership with MFPD, many other residents undertook these efforts independently. This sort of behavior is consistent with studies of informal interactions between neighbors in the WUI as a contributing factor to defensible space, as residents feel a responsibility to protect each other (a sort of wildfire vulnerability peer pressure) [61-63]. It is also consistent with previous findings that these sorts of community relationships are critical elements of success in communities where CWPPs have been tested by subsequent wildfire [64].

The three types of partnerships developed in Montecito are emblematic of the relationships called for in fire vulnerability reduction frameworks and are critical to enacting the strategies for vulnerability reduction [16-18]. While fire scientists can continue to debate the definition of success associated with wildfires, it is clear from the data synthesized here that success in Montecito, along with the coastal Santa Barbara front, is defined as zero fatalities and minimal infrastructure damage. Given the projected losses, that was achieved in Montecito during the Thomas Fire.

\section{Conclusions}

There is a clear need to improve wildfire mitigation planning by integrating the social and biophysical elements across all three components of wildfire vulnerability [65], but also a need to document the outcomes of such efforts when wildfires occur. This is, in some respects, more difficult to do than an experimental study given the lack of controlled environment, the challenging conditions of the post-fire environment in impacted communities, and the myriad of social and biophysical factors that contribute to outcomes across multiple spatio-temporal scales. However, such case studies can help to identify what factors future studies might seek to analyze across a broader set of events, or in more controlled experiments. They can also serve to validate more theoretical findings of prior studies across the biophysical to social spectrum.

Here, connecting mitigation actions to post-fire observations reported in Montecito through the tri-part lens of vulnerability demonstrates that all three components must be addressed to successfully reduce vulnerability to wildfire elsewhere in the US and globally. It is important to recognize the complexity of the socio-ecological system that produces the observed outcome, as research too often seeks to reconstruct or identify the relevance of a single factor (e.g., meteorology) without the broader context of the event. No single agent was identified as the primary determinant of relatively minimal loss during the Thomas Fire in Montecito; rather, interviews, geospatial data, and historical documentation demonstrated that a range of mitigation strategies that have been presented 
in prior research contributed to the observed outcome, including fuel modification, road clearance modification, planning, social networks, community partnerships, defensible space, and education. Furthermore, mitigation of vulnerability did not occur overnight, but rather, over a 20+ year period during which incremental increases and steps were taken.

No community can completely eliminate wildfire vulnerability as long as there is fuel in the form of homes and vegetation, and even well-prepared communities must be diligent in maintaining ongoing communications and preparedness. It is also critical to recognize that having sufficient time between fire ignition and advancement upon a community is a fundamental determinant of how the fire will ultimately impact that community, and whether firefighters will be focused on evacuation versus home protection. However, mitigation activities identified here were critical to preparing Montecito for the inevitability of a wildfire, and to supporting both safe evacuation and safe engagement by firefighters of the fire around homes during the 2017 Thomas Fire. The strategies implemented by Montecito may not necessarily work for every community archetype, but can inform place-based assessment of vulnerability reduction based on similarities in exposure, sensitivity, and adaptive capacity. Such approaches must be adopted, and quickly, to stymie the rise of wildfire disasters [10].

Funding: This research received no external funding, however, see Conflicts of Interest.

Acknowledgments: The authors gratefully acknowledge the cooperation and participation of the Montecito Fire Protection District and the interviewees who provided considerable additional data, photos, and videos to support the development of the Retrospective Report. We want to particularly thank Kerry Kellogg, Maeve Juarez, and Rob Hazard for additional data that improved the accuracy of the geospatial analyses, and to Geo Elements, LLC, personnel for considerable insights and explanation, particularly of fire management and suppression terms and processes.

Conflicts of Interest: The authors acknowledge that they were paid consultants to the Montecito Fire Protection District for the data collection and analysis that appeared in the report synthesized and referenced here. Data collection and analysis were designed by Geo Elements LLC to meet the requirements of MFPD, not for scientific analyses, and MFPD owns all data. The Authors had full permission from MFPD to independently, re-analyze, and synthesize the findings of the referenced report in a scientific framework for this case report, but MFPD did not provide any financial support for the completion of this case report.

\section{References}

1. Radeloff, V.C.; Helmers, D.P.; Kramer, H.A.; Mockrin, M.H.; Alexandre, P.M.; Bar-Massada, A.; Butsic, V.; Hawbaker, T.J.; Martinuzzi, S.; Syphard, A.D.; Stewart, S.I. Rapid growth of the US wildland-urban interface raises wildfire risk. Proc. Natl. Acad. Sci. USA 2018, 115, 3314-3319. [CrossRef] [PubMed]

2. Balch, J.K.; Bradley, B.A.; Abatzoglou, J.T.; Nagy, R.C.; Fusco, E.J.; Mahood, A.L. Human-started wildfires expand the fire niche across the United States. Proc. Natl. Acad. Sci. USA 2017, 114, 2946-2951. [CrossRef] [PubMed]

3. Kramer, H.A.; Mockrin, M.H.; Alexandre, P.M.; Stewart, S.I.; Radeloff, V.C. Where wildfires destroy buildings in the US relative to the wildland-urban interface and national fire outreach programs. Int. J. Wildland Fire 2018, 27, 329-341. [CrossRef]

4. Nagy, R.; Fusco, E.; Bradley, B.; Abatzoglou, J.T.; Balch, J. Human-related ignitions increase the number of large wildfires across US ecoregions. Fire 2018, 1, 4. [CrossRef]

5. Abatzoglou, J.T.; Balch, J.K.; Bradley, B.A.; Kolden, C.A. Human-related ignitions concurrent with high winds promote large wildfires across the USA. Int. J. Wildland Fire 2018, 27, 377-386. [CrossRef]

6. Abatzoglou, J.T.; Williams, A.P. Impact of anthropogenic climate change on wildfire across western US forests. Proc. Natl. Acad. Sci. USA 2016, 113, 11770-11775. [CrossRef] [PubMed]

7. Barbero, R.; Abatzoglou, J.T.; Larkin, N.K.; Kolden, C.A.; Stocks, B. Climate change presents increased potential for very large fires in the contiguous United States. Int. J. Wildland Fire 2015, 24, 892-899. [CrossRef]

8. Balch, J.; Schoennagel, T.; Williams, A.; Abatzoglou, J.; Cattau, M.; Mietkiewicz, N.; St Denis, L. Switching on the Big Burn of 2017. Fire 2018, 1, 17. [CrossRef] 
9. Bowman, D.M.; Moreira-Muñoz, A.; Kolden, C.A.; Chávez, R.O.; Muñoz, A.A.; Salinas, F.; González-Reyes, Á.; Rocco, R.; de la Barrera, F.; Williamson, G.J.; Borchers, N. Human-environmental drivers and impacts of the globally extreme 2017 Chilean fires. Ambio 2018. [CrossRef] [PubMed]

10. Bowman, D.M.; Williamson, G.J.; Abatzoglou, J.T.; Kolden, C.A.; Cochrane, M.A.; Smith, A.M.S. Human exposure and sensitivity to globally extreme wildfire events. Nat. Ecol. Evol. 2017, 1, 0058. [CrossRef] [PubMed]

11. Lareau, N.P.; Nauslar, N.J.; Abatzoglou, J.T. The Carr Fire Vortex: A Case of Pyro-tornadogenesis? Geophys. Res. Lett. 2018, 45, 13-107. [CrossRef]

12. Nauslar, N.; Abatzoglou, J.; Marsh, P. The 2017 North Bay and Southern California Fires: A Case Study. Fire 2018, 1, 18. [CrossRef]

13. Abatzoglou, J.T.; Williams, A.P.; Boschetti, L.; Zubkova, M.; Kolden, C.A. Global patterns of interannual climate-fire relationships. Glob. Change Biol. 2018, 24, 5164-5175. [CrossRef] [PubMed]

14. Moritz, M.A.; Batllori, E.; Bradstock, R.A.; Gill, A.M.; Handmer, J.; Hessburg, P.F.; Leonard, J.; McCaffrey, S.; Odion, D.C.; Schoennagel, T.; Syphard, A.D. Learning to coexist with wildfire. Nature 2014, 515, 58. [CrossRef] [PubMed]

15. Schoennagel, T.; Balch, J.K.; Brenkert-Smith, H.; Dennison, P.E.; Harvey, B.J.; Krawchuk, M.A.; Mietkiewicz, N.; Morgan, P.; Moritz, M.A.; Rasker, R.; Turner, M.G. Adapt to more wildfire in western North American forests as climate changes. Proc. Natl. Acad. Sci. USA 2017, 114, 4582-4590. [CrossRef] [PubMed]

16. Eriksen, C.; Simon, G. The Affluence-Vulnerability Interface: Intersecting scales of risk, privilege and disaster. Environ. Plann. A 2017, 49, 293-313. [CrossRef]

17. Wigtil, G.; Hammer, R.B.; Kline, J.D.; Mockrin, M.H.; Stewart, S.I.; Roper, D.; Radeloff, V.C. Places where wildfire potential and social vulnerability coincide in the coterminous United States. Int. J. Wildland Fire 2016, 25, 896-908. [CrossRef]

18. Gaither, C.J.; Poudyal, N.C.; Goodrick, S.; Bowker, J.M.; Malone, S.; Gan, J. Wildland fire risk and social vulnerability in the Southeastern United States: An exploratory spatial data analysis approach. Forest Policy Econ. 2011, 13, 24-36. [CrossRef]

19. Pyne, S.J. Fire in America: A Cultural History of Wildland and Rural Fire; University of Washington Press: Seattle, WA, USA, 2017.

20. Mutch, R.W. Wildland Fires and Ecosystems-A Hypothesis. Ecology 1970, 51, 1046-1051. [CrossRef]

21. Ager, A.A.; Day, M.A.; Finney, M.A.; Vance-Borland, K.; Vaillant, N.M. Analyzing the transmission of wildfire exposure on a fire-prone landscape in Oregon, USA. Forest Ecol. Manag. 2014, 334, 377-390. [CrossRef]

22. Ager, A.A.; Vaillant, N.M.; Finney, M.A. A comparison of landscape fuel treatment strategies to mitigate wildland fire risk in the urban interface and preserve old forest structure. Forest Ecol. Manag. 2010, 259, 1556-1570. [CrossRef]

23. Finney, M.A.; Seli, R.C.; McHugh, C.W.; Ager, A.A.; Bahro, B.; Agee, J.K. Simulation of long-term landscape-level fuel treatment effects on large wildfires. Int. J. Wildland Fire 2008, 16, 712-727. [CrossRef]

24. Stratton, R.D. Assessing the effectiveness of landscape fuel treatments on fire growth and behavior. J. Forestry 2004, 102, 32-40. [CrossRef]

25. Hudak, A.T.; Rickert, I.; Morgan, P.; Strand, E.; Lewis, S.A.; Robichaud, P.; Hoffman, C.; Holden, Z.A. Review of Fuel Treatment Effectiveness in Forests and Rangelands and a Case Study from the 2007 Megafires in Central Idaho USA; Gen. Tech. Rep. RMRS-GTR-252; USDA Forest Service: Fort Collins, CO, USA, 2011.

26. Safford, H.D.; Stevens, J.T.; Merriam, K.; Meyer, M.D.; Latimer, A.M. Fuel treatment effectiveness in California yellow pine and mixed conifer forests. Forest Ecol. Manag. 2012, 274, 17-28. [CrossRef]

27. Wimberly, M.C.; Cochrane, M.A.; Baer, A.D.; Pabst, K. Assessing fuel treatment effectiveness using satellite imagery and spatial statistics. Ecol. Appl. 2009, 19, 1377-1384. [CrossRef] [PubMed]

28. Agee, J.K.; Skinner, C.N. Basic principles of forest fuel reduction treatments. Forest Ecol. Manag. 2005, 211, 83-96. [CrossRef]

29. Agee, J.K.; Bahro, B.; Finney, M.A.; Omi, P.N.; Sapsis, D.B.; Skinner, C.N.; Van Wagtendonk, J.W.; Weatherspoon, C.P. The use of shaded fuelbreaks in landscape fire management. Forest Ecol. Manag. 2000, 127, 55-66. [CrossRef] 
30. Schoennagel, T.; Nelson, C.R.; Theobald, D.M.; Carnwath, G.C.; Chapman, T.B. Implementation of National Fire Plan treatments near the wildland-urban interface in the western United States. Proc. Natl. Acad. Sci. USA 2009. [CrossRef] [PubMed]

31. Evers, C.R.; Ager, A.A.; Nielsen-Pincus, M.; Palaiologou, P.; Bunzel, K. Archetypes of community wildfire exposure from national forests of the western US. Landscape Urban Plan. 2019, 182, 55-66. [CrossRef]

32. Calkin, D.E.; Cohen, J.D.; Finney, M.A.; Thompson, M.P. How risk management can prevent future wildfire disasters in the wildland-urban interface. Proc. Natl. Acad. Sci. USA 2014, 111, 746-751. [CrossRef] [PubMed]

33. Cohen, J.D. Relating flame radiation to home ignition using modeling and experimental crown fires. Can. J. Forest Res. 2004, 34, 1616-1626. [CrossRef]

34. Mell, W.E.; Manzello, S.L.; Maranghides, A.; Butry, D.; Rehm, R.G. The wildland-urban interface fire problem-current approaches and research needs. Int. J. Wildland Fire 2010, 19, 238-251. [CrossRef]

35. Paveglio, T.B.; Carroll, M.S.; Jakes, P.J. Alternatives to evacuation during wildland fire: Exploring adaptive capacity in one Idaho community. Environ Hazards 2010, 9, 379-394. [CrossRef]

36. Jakes, P.J.; Langer, E.L. The adaptive capacity of New Zealand communities to wildfire. Int. J. Wildland Fire 2012, 21, 764-772. [CrossRef]

37. Paveglio, T.B.; Carroll, M.S.; Jakes, P.J.; Prato, T. Exploring the social characteristics of adaptive capacity for wildfire: insights from Flathead County, Montana. Hum. Ecol. Rev. 2012, 19, 110-124.

38. Paveglio, T.B.; Moseley, C.; Carroll, M.S.; Williams, D.R.; Fischer, A.P.; Davis, E.J. Categorizing the social context of the wildland urban interface: Adaptive capacity for wildfire and community "archetypes". Forest Sci. 2015, 61, 298-310. [CrossRef]

39. CALFIRE. Available online: www.fire.ca.gov (accessed on 7 January 2019).

40. Paveglio, T.B.; Jakes, P.J.; Carroll, M.S.; Williams, D.R. Understanding social complexity within the wildland-urban interface: a new species of human habitation? Environ. Manage. 2009, 43, 1085-1095. [CrossRef] [PubMed]

41. Carroll, M.; Paveglio, T. Using community archetypes to better understand differential community adaptation to wildfire risk. Phil. Trans. R. Soc. B 2016, 371, 20150344. [CrossRef] [PubMed]

42. Owen, G.; McLeod, J.D.; Kolden, C.A.; Ferguson, D.B.; Brown, T.J. Wildfire management and forecasting fire potential: the roles of climate information and social networks in the southwest United States. Weather Clim. Soc. 2012, 4, 90-102. [CrossRef]

43. Akama, Y.; Chaplin, S.; Fairbrother, P. Role of social networks in community preparedness for bushfire. Int. J. Disast. Resilience Built Environ. 2014, 5, 277-291. [CrossRef]

44. Fischer, A.P.; Spies, T.A.; Steelman, T.A.; Moseley, C.; Johnson, B.R.; Bailey, J.D.; Ager, A.A.; Bourgeron, P.; Charnley, S.; Collins, B.M.; et al. Wildfire risk as a socioecological pathology. Front. Ecol. Environ. 2016, 14, 276-284. [CrossRef]

45. Paveglio, T.B.; Abrams, J.; Ellison, A. Developing fire adapted communities: the importance of interactions among elements of local context. Soc. Natur. Resour. 2016, 29, 1246-1261. [CrossRef]

46. Paveglio, T.B.; Carroll, M.S.; Stasiewicz, A.M.; Williams, D.R.; Becker, D.R. Incorporating Social Diversity into Wildfire Management: Proposing "Pathways" for Fire Adaptation. Forest Sci. 2018, 64, 515-532. [CrossRef]

47. Montecito Fire Protection District. A Defensible Community? A Retrospective Study of Montecito Fire Protection District's Wildland Fire Program during the 2017 Thomas Fire; Montecito Fire Protection District: Montecito, CA, USA, 2018.

48. Montecito Fire Protection District. Montecito Community Wildfire Protection Plan; Montecito Fire Protection District: Montecito, CA, USA, 2016.

49. Kolden, C.A.; Abatzoglou, J.T. Spatial distribution of wildfires ignited under katabatic versus non-katabatic winds in mediterranean Southern California USA. Fire 2018, 1, 19. [CrossRef]

50. Mensing, S.A.; Michaelsen, J.; Byrne, R. A 560-year record of Santa Ana fires reconstructed from charcoal deposited in the Santa Barbara Basin, California. Quaternary Res. 1999, 51, 295-305. [CrossRef]

51. Keeley, J.E.; Fotheringham, C.J. Historic fire regime in southern California shrublands. Conserv. Biol. 2001, 15, 1536-1548. [CrossRef]

52. Syphard, A.D.; Radeloff, V.C.; Keeley, J.E.; Hawbaker, T.J.; Clayton, M.K.; Stewart, S.I.; Hammer, R.B. Human influence on California fire regimes. Ecol. Appl. 2007, 17, 1388-1402. [CrossRef] [PubMed]

53. Calkin, D.E.; Stonesifer, C.S.; Thompson, M.P.; McHugh, C.W. Large airtanker use and outcomes in suppressing wildland fires in the United States. Int. J. Wildland Fire 2014, 23, 259-271. [CrossRef] 
54. California Department of Forestry and Fire Protection. Jesusita Fire Burnover; California Department of Forestry and Fire Protection: Sacramento, CA, USA. 2009.

55. Mangan, R. Wildland Firefighter Fatalities in the United States: 1990-2006, NWCG PMS, 841; National Interagency Fire Center: Boise, ID, USA, 2007.

56. Santa Rose Press Democrat. Available online: https://www.pressdemocrat.com/news/4493945-181/ remains-of-two-more-valley?gallery $=4495798 \&$ artslide $=1$ (accessed on 28 January 2019).

57. San Jose Mercury News. Available online: https://www.mercurynews.com/2017/10/11/hundreds-missingin-wine-country-fires-here-are-some-of-their-stories / (accessed on 28 January 2019).

58. National Public Radio. Available online: https://www.npr.org/2018/07/28/633471082/death-toll-innorthern-californias-carr-fire-rises-to-5 (accessed on 28 January 2019).

59. Keeley, J.E.; Keeley, S.C. Post-fire regeneration of southern California chaparral. Am. J. Bot. 1981, 68, 524-530. [CrossRef]

60. Kunadharaju, K.; Smith, T.D.; DeJoy, D.M. Line-of-duty deaths among US firefighters: an analysis of fatality investigations. Accident Anal. Prev. 2011, 43, 1171-1180. [CrossRef] [PubMed]

61. McCaffrey, S.M.; Stidham, M.; Toman, E.; Shindler, B. Outreach programs, peer pressure, and common sense: what motivates homeowners to mitigate wildfire risk? Environ. Manage. 2011, 48, 475-488. [CrossRef] [PubMed]

62. Brenkert-Smith, H.; Champ, P.A.; Flores, N. Insights into wildfire mitigation decisions among wildland-urban interface residents. Soc. Natur. Resour. 2006, 19, 759-768. [CrossRef]

63. Brenkert-Smith, H. Building bridges to fight fire: the role of informal social interactions in six Colorado wildland-urban interface communities. Int. J. Wildland Fire 2010, 19, 689-697. [CrossRef]

64. Jakes, P.J.; Sturtevant, V. Trial by fire: community wildfire protection plans put to the test. Int. J. Wildland Fire 2013, 22, 1134-1143. [CrossRef]

65. Ager, A.A.; Kline, J.D.; Fischer, A.P. Coupling the biophysical and social dimensions of wildfire risk to improve wildfire mitigation planning. Risk Anal. 2015, 35, 1393-1406. [CrossRef] [PubMed]

(C) 2019 by the authors. Licensee MDPI, Basel, Switzerland. This article is an open access article distributed under the terms and conditions of the Creative Commons Attribution (CC BY) license (http:/ / creativecommons.org/licenses/by/4.0/). 